University of Nebraska - Lincoln

DigitalCommons@University of Nebraska - Lincoln

Faculty Publications, Department of Child, Youth, and Family Studies

2020

Comparison of Urban and Rural Physical Activity and Outdoor Play Environments of Childcare Centers and Family Childcare Homes

Danae Dinkel

Dipti Dev

Yage Guo

Ami Sedani

Emily Hulse

See next page for additional authors

Follow this and additional works at: https://digitalcommons.unl.edu/famconfacpub

Part of the Developmental Psychology Commons, Family, Life Course, and Society Commons, Other Psychology Commons, and the Other Sociology Commons

This Article is brought to you for free and open access by the Child, Youth, and Family Studies, Department of at DigitalCommons@University of Nebraska - Lincoln. It has been accepted for inclusion in Faculty Publications, Department of Child, Youth, and Family Studies by an authorized administrator of DigitalCommons@University of Nebraska - Lincoln. 
Authors

Danae Dinkel, Dipti Dev, Yage Guo, Ami Sedani, Emily Hulse, Zainab Rida, and Kayla Abel 


\title{
Comparison of Urban and Rural Physical Activity and Outdoor Play Environments of Childcare Centers and Family Childcare Homes
}

\author{
Danae Dinkel, $\mathrm{PhD},{ }^{1}$ Dipti Dev, $\mathrm{PhD}^{2}$ Yage Guo, $\mathrm{MS}^{2}$ \\ Ami Sedani, MPH, ${ }^{3,4}$ Emily Hulse, $M S^{5}{ }^{5}$ \\ Zainab Rida, PhD, RD, LMNT, ${ }^{6}$ Kayla Abel, MS, RD, LMNT ${ }^{3,7}$ \\ 1 School of Health and Kinesiology, University of Nebraska at Omaha \\ 2 Department of Child, Youth, and Family Studies, University of \\ Nebraska-Lincoln \\ 3 Nebraska Department of Health \& Human Services, Lincoln, Nebraska \\ 4 University of Oklahoma Health Sciences Center, Oklahoma City \\ 5 Children's Hospital and Medical Center, Center for the Child \& Community, \\ Lincoln, Nebraska \\ 6 Nebraska Department of Education, Lincoln, Nebraska \\ 7 Family Service WIC, Lincoln, Nebraska \\ Correspondence - Danae Dinkel, PhD, School of Health and Kinesiology, University of $\mathrm{Ne}$ - \\ braska at Omaha, 6001 Dodge St, Omaha, NE 68182 (dmdinkel@unomaha.edu).
}

\begin{abstract}
The purpose of this study was to examine the physical activity environment in childcare programs across type (childcare centers [CCCs] and family childcare homes [FCCHs]) and geographic location (urban and rural) as assessed by physical activity best practices according to the Go Nutrition and Physical Activity Self-assessment in Child Care. Results showed CCCs compared with FCCHs reported higher achievement of best practices. Further, urban childcare programs (CCCs and FCCHs) reported higher achievement of best practices in comparison to rural childcare programs. There is a need to deliver targeted interventions that promote children's physical activity in $\mathrm{FCCH}$ and $\mathrm{CCC}$ in rural areas.
\end{abstract}

Keywords: childcare, day care, physical activity, play, policy

Published in Family and Community Health 43:4 (October-December 2020), pp 264-275. DOI: $10.1097 / F C H .0000000000000267$

Copyright (c 2020 Wolters Kluwer Health, Inc. Used by permission. 
G lobally, approximately 41 million children younger than 5 years are overweight or obese. ${ }^{1}$ Within the United States (US), $8.1 \%$ of 0 - to 2-year-olds and $22.8 \%$ of 2 - to 5 -year-olds are overweight or obese. ${ }^{2}$ Being overweight or obese as a child increases one's risk for obesity in adulthood and developing consequential chronic health conditions such as type 2 diabetes and cardiovascular disease. ${ }^{1,3-5}$ Due to the high rates of overweight/ obesity and associated chronic conditions, national and international organizations alike have emphasized the need for all sectors (e.g., government and education) to make health a priority to have a greater impact on childhood obesity. ${ }^{1,6-9}$

One sector that has been shown to impact health behaviors in early childhood is childcare settings. In the US, approximately $62 \%$ of children younger than 6 years receive some form of nonparental regular childcare. ${ }^{10,11}$ Thus, the childcare environment can have a significant impact on children's development including health behaviors such as physical activity (PA). ${ }^{12-16} \mathrm{PA}$ is an important behavior to establish in early childhood because PA cannot only help young children to attain energy balance and subsequently positively impact weight, but it also positively contributes to numerous developmental milestones (physical, social, and psychological). ${ }^{17,18}$ Importantly, specific recommendations from national and international organizations such as the World Health Organization and the US Department of Health and Human Services are to provide daily opportunities for PA consistently throughout the day. ${ }^{1,6}$ Unfortunately, up to one-half of children may not be obtaining enough PA in childcare. ${ }^{19}$ Efforts are needed to better implement policies and practices targeting increases in PA in childcare settings. ${ }^{17,19}$

An important consideration when developing policies and practices to improve children's PA in childcare is to understand the type of childcare setting. Two types of childcare settings include childcare centers (CCCs) and family childcare homes (FCCHs). CCCs typically consist of multiple classrooms separated by age, while FCCHs are typically a smaller group of children of differing ages within one area. ${ }^{20} \mathrm{CCC}$ usually have bigger facilities and more staff as compared with FCCHs, thus FCCHs may lack indoor space required to provide PA and fewer staff. However, owing to fewer staff to manage, and that the $\mathrm{FCCH}$ owner is the provider, FCCH providers may feel more accountable and have flexibility to implement PA policies compared with centers. ${ }^{21,22}$ On the other hand, in counties where FCCHs may not require licensing and 
have fewer regulations, they may have less motivation to implement PA best practices. Due to the variety of potential variances, different types of childcare settings may require unique resources and interventions. Other research has found FCCHs may be less likely than CCCs to offer a variety of fixed and portable play equipment. ${ }^{23}$ Further, CCCs may have more space to support outdoor PA through the provision of wide, curvy wheeled pathways, which have been associated with increased motivation for PA for preschool children. ${ }^{24}$ More research is needed to understand what specific areas may require distinctive approaches to increase PA.

In addition to the type of setting, geographic location may have an impact on the achievement of PA policies and practices. ${ }^{25}$ Specifically, some research suggests that rural children may be more likely to receive nonparental care. ${ }^{26}$ Previous research has found that children and adults in rural counties are more likely to be overweight or obese. ${ }^{27,28}$ While studies have not found differences in the amount of PA accumulated between urban and rural childcare facilities, the type of resources available and/or type of resources needed by childcare providers could vary. ${ }^{29}$ For example, rural facilities may have limited access to in-person staff training and lack funding/resources to encourage PA. ${ }^{30}$ Taking these distinctive characteristics into account as they potentially influence the childcare PA environment and practices is the first step for implementing targeted PA interventions based on the childcare setting environment.

An intervention that has been utilized in both CCCs and FCCHs in urban and rural settings and deemed to be one of the best early childhood programs for prevention of childhood obesity is Go Nutrition and Physical Activity Self-Assessment in Child Care (Go NAP SACC). ${ }^{11,16,31-39}$ Go NAP SACC is designed to assist childcare providers to improve the health of children through the implementation of policies and practices with a specific focus on PA. ${ }^{32,33}$ Participation in Go NAP SACC consists of completion of a pre-/post self-assessment, workshops focused on healthy eating and PA, as well as action planning with technical assistance provided by a Go NAP SACC trainer. The Go NAP SACC self-assessment instrument was developed based on extensive research and national health recommendations to identify evidence-based best practices indicative of meeting and exceeding childcare standards related to increased PA in children. ${ }^{11,35-40}$ The 
PA best practice guidelines include recommendations for active opportunities, fixed play environment, portable play environment, staff behavior, staff training/education, and policies. ${ }^{32,33}$ Despite its widespread use, minimal research has utilized the Go NAP SACC tool to determine if differences exist between childcare settings and geographic location. ${ }^{16,34}$ Therefore, the purpose of this study was to compare achievement of meeting evidence-based PA childcare standards between: (1) CCCs and FCCHs in urban areas; (2) CCCs and FCCHs in rural areas; (3) CCCs across geographic location (urban-rural); and (4) FCCHs across geographic location (urban-rural).

\section{Methods}

\section{Study design}

Using a cross-sectional design, all eligible childcare settings in $\mathrm{Ne}$ braska were invited to participate in the study between August 2014 and August 2016. Two sections of the Go NAP SACC self-assessments covering 9 categories were used for this study: infant and child PA and outdoor play and learning. ${ }^{41}$ Once individuals agreed to participate in Go NAP SACC, they completed the baseline self-assessment. Assessments were completed by the center director at CCCs or owner of FCCHs. The assessment was hosted through a secured online server at the University of Nebraska-Lincoln. ${ }^{32}$ The University of NebraskaLincoln Institutional Review Board deemed the study exempt due to the lack of identifying information given to the researchers.

\section{Sample}

Participants were CCCs $(n=203)$ and FCCHs $(n=314)$ who completed the Go NAP SACC baseline assessment during the study's time frame. All licensed CCCs $(n=985)$ and FCCHs $(n=2151)$ in Nebraska who provided care to children younger than 6 years were eligible to participate. Additionally, unlicensed FCCHs were eligible to participate. Childcare settings were actively recruited for Go NAP SACC through a variety of methods including e-mails, newsletters, organizations that Go NAP SACC trainers worked for (e.g., Nebraska Extension, nonprofit organizations, and local healthcare systems), the NE Go NAP SACC 
online training calendar, the Nebraska Department of Education's Early Childhood Professional Record System, and word of mouth. Once directors/providers agreed to participate in Go NAP SACC, they completed the baseline self-assessment. Directors/providers self-identified as either a CCC or FCCH as well as if they participated in the Child and Adult Care Food Program (CACFP), a federal program that reimburses providers for serving healthy meals and snacks. ${ }^{42}$

In this study, counties were used as a basis for rural-urban designation into 1 of 3 categories of metropolitan, micropolitan, and rural. ${ }^{43}$ Metropolitan status was defined as any area with a population of 50 000 or more residents ( $n=2$ counties) an additional 7 of which were metropolitan "outlying" counties $(n=7)$. Micropolitan status was defined as an area with a population of 10000 or more residents ( $n=$ 10). Rural status consisted of any population smaller than micropoli$\tan (n=74)$. For the purpose of the analysis and consistent with other literature, micropolitan and rural counties were combined to be able to compare differences across urban (metropolitan) and rural (micropolitan and rural).44

\section{Measure}

Go NAP SACC offers 6 independent self-assessments to address different health behaviors. ${ }^{45}$ The 2 Go NAP SACC self-assessments related to PA covering 9 categories were used for this study: infant and child PA and outdoor play and learning. ${ }^{41}$ Due to differences in the CCC and FCCH environment, Go NAP SACC provides separate self-assessments for CCCs and FCCHs. Our analysis compared similar questions between the assessments. The infant and child PA self-assessment consists of 5 categories with a total of 20 questions: time provided $(n=5)$, indoor play environment $(n=4)$, daily practices $(n=4)$, educational and professional development $(n=6)$, and policy $(n=1)$. The outdoor play and learning self-assessment consists of questions covering 4 categories with a total of 15 questions: outdoor playtime $(n=3)$, outdoor play environment $(n=7)$, educational and professional development $(n=4)$, and policy $(n=1)$. All questions are based on evidence-based best practices that meet or exceed childcare standards. ${ }^{33}$ Examples from each section can be found in Table 1, and the entire assessment can be found on the Go NAP SACC website - https://gonapsacc.org/ self-assessment-materials. Providers answered on a 4-point Likert 
Table 1. Sample Questions From Go NAP SACC Physical Activity Self Assessments ${ }^{a}$

\begin{tabular}{|c|c|c|}
\hline Question & Response & Choices \\
\hline \multicolumn{3}{|l|}{ Infant and child physical activity } \\
\hline Time provided & $\begin{array}{l}\text { Our program/l offer tummy time to } \\
\text { noncrawling infants: }\end{array}$ & $\begin{array}{l}\text { - } 1 \text { time per day or less } \\
\text { - } 2 \text { times per day } \\
\text { - } 3 \text { times per day } \\
\text { - } 4 \text { times per day or more }\end{array}$ \\
\hline Indoor play environment & $\begin{array}{l}\text { I/teachers offer portable play equipment to } \\
\text { children during indoor free playtime }\end{array}$ & $\begin{array}{l}\text { - Rarely or never } \\
\text { - Sometimes } \\
\text { - Often } \\
\text { - At least a few items are } \\
\text { always available to } \\
\text { encourage physical } \\
\text { activity }\end{array}$ \\
\hline Daily practices & $\begin{array}{l}\text { To manage challenging behaviors, I/teachers } \\
\text { may take away time for physical activity or } \\
\text { remove children from physically active } \\
\text { playtime for longer than } 5 \text { min }\end{array}$ & $\begin{array}{l}\text { - Always } \\
\text { - Often } \\
\text { - Sometimes } \\
\text { - Never }\end{array}$ \\
\hline $\begin{array}{l}\text { Education and professional } \\
\text { development }\end{array}$ & $\begin{array}{l}\text { I/teachers/staff receive professional } \\
\text { development on children's physical activity }\end{array}$ & $\begin{array}{l}\text { - Never } \\
\text { - Less than } 1 \text { time per year } \\
\text { - } 1 \text { time per year } \\
\text { - } 2 \text { times per year or more }\end{array}$ \\
\hline Policy & $\begin{array}{l}\text { My/our written policy on physical activity } \\
\text { includes the following topics: } \\
\text { - Amount of time provided each day for } \\
\text { indoor and outdoor physical activity } \\
\text { - Limiting long periods of seated time for } \\
\text { children } \\
\text { - Shoes and clothes that allow children } \\
\text { and teachers to actively participate in } \\
\text { physical activity } \\
\text { - Teacher practices that encourage } \\
\text { physical activity } \\
\text { - Not taking away physical activity time or } \\
\text { removing children from long periods of } \\
\text { physically active playtime to manage } \\
\text { challenging behaviors } \\
\text { - Planned and informal physical activity } \\
\text { education } \\
\text { - Professional development on children's } \\
\text { physical activity } \\
\text { - Education for families on children's } \\
\text { physical activity }\end{array}$ & $\begin{array}{l}\text { - No written policy or } \\
\text { policy does not include } \\
\text { these topics } \\
\text { - } 1 \text {-3 topics } \\
\text { 4-6 topics } \\
\text { - } 7 \text {-8 topics }\end{array}$ \\
\hline
\end{tabular}


Table 1. Sample Questions From Go NAP SACC Physical Activity Self Assessments ${ }^{a}$ (continued)

\begin{tabular}{|c|c|c|}
\hline Question & Response & Choices \\
\hline \multicolumn{3}{|l|}{ Outdoor play and learning } \\
\hline Outdoor playtime & $\begin{array}{l}\text { I/our program does the following types of } \\
\text { activities with children outdoors: } \\
\text { - Free play } \\
\text { - Structured learning opportunities } \\
\text { - Seasonal outdoor activities } \\
\text { - Walking trips } \\
\text { - Outdoor field trips }\end{array}$ & $\begin{array}{l}\text { - None } \\
\text { - } 1 \text { activity type } \\
\text { - 2-3 activity types } \\
\text { - } 4-5 \text { activity types }\end{array}$ \\
\hline Outdoor play environment & $\begin{array}{l}\text { An open area for outdoor games, activities, } \\
\text { and events is: }\end{array}$ & $\begin{array}{l}\text { - Not available } \\
\text { - Large enough for some } \\
\text { children to run around } \\
\text { - Large enough for most } \\
\text { children to run around } \\
\text { safely } \\
\text { - Large enough for all } \\
\text { children to run around } \\
\text { safely }\end{array}$ \\
\hline $\begin{array}{l}\text { Education and professional } \\
\text { development }\end{array}$ & $\begin{array}{l}\text { I/teacher/staff complete professional } \\
\text { development on outdoor play and learning: }\end{array}$ & $\begin{array}{l}\text { - Never } \\
\text { - Less than } 1 \text { time per year } \\
\text { - } 1 \text { time per year } \\
\text { - } 2 \text { times per year or more, } \\
\text { including at least } 1 \\
\text { in-person or online } \\
\text { training, when available }\end{array}$ \\
\hline Policy & $\begin{array}{l}\text { My/our program's written policy on outdoor } \\
\text { play learning includes the following topics: } \\
\text { - Amount of outdoor playtime provided } \\
\text { each day } \\
\text { - Ensuring adequate total playtime on } \\
\text { inclement weather days } \\
\text { - Shoes and clothes that allow children to } \\
\text { play outdoors in all seasons } \\
\text { - Safe sun exposure for children } \\
\text { - Not taking away outdoor playtime to } \\
\text { manage challenging behaviors } \\
\text { - My participation in professional } \\
\text { development on outdoor play and learning } \\
\text { - Education for families on outdoor play and } \\
\text { learning }\end{array}$ & $\begin{array}{l}\text { - No written policy or } \\
\text { policy does not include } \\
\text { these topics } \\
\text { - } 1-2 \text { topics } \\
\text { - 3-5 topics } \\
\text { - } 6-7 \text { topics }\end{array}$ \\
\hline
\end{tabular}

a. The full assessments can be found at https://gonapsacc.org/self-assessment-materials. 
scale developed by previous Go NAP SACC research. ${ }^{46}$ Answers varied based on the question and were coded as $1=$ marginally meeting childcare standards, $2=$ meeting childcare standards, $3=$ exceeding childcare standards, and $4=$ far exceeding childcare standards and meeting best practice based on Go NAP SACC recommended best practices. The Go NAP SACC self-assessments have been shown to have acceptable reliability and validity and have been widely used in childcare studies. ${ }^{34-39}$ Assessments were completed by the center director at CCCs or owner of FCCHs. The assessment was hosted through a secured online server at the University of Nebraska-Lincoln. ${ }^{32,47}$

\section{Statistical analyses}

Using the results from the Go NAP SACC baseline self-assessments for the 2 PA-related sections, 20 items from the infant and child PA and 15 items for the outdoor play and learning were analyzed, with each individual question representing a best practice in childcare. First, descriptive statistics were calculated. Due to the likelihood of higher rates of best practices among providers who participate in the CACFP and increased access to trainings and material related to PA, participation in the CACFP was identified as a potential confounder. Two multivariate analyses of covariance were used to determine whether there were any statistically significant differences between the adjusted means of PA best practices at CCCs and FCCHs in rural communities compared with urban communities, having controlled for CACFP participation in each of the 2 self-assessments. The Sidak-Bonferroni correction was applied to adjust the multiple comparisons. ${ }^{48}$ The $P$ value for the infant and child PA items was Sidak- Bonferroni $=1-(1-0.05)^{0.05}=$ .003 , and the $P$ value for outdoor play and learning items was SidakBonferroni $=1-(1-0.05)^{0.067}=.003$.

\section{Results}

A total of 698 providers began an assessment in the online database, but only 517 (FCCHs = 314, CCCs=203) completed the baseline assessment and thus were used for analysis. Of those who completed, approximately 7544 children from different age groups received care 
Table 2. Characteristics of FCCHs and CCCs Facilities ${ }^{a}$

\begin{tabular}{lrrrr} 
& FCCH $\boldsymbol{n}$ & CCC $\boldsymbol{n}$ & Total N & Percentage \\
\hline Providers who completed, $\mathrm{n}$ & 314 & 203 & 698 & $74.07 \%$ \\
Total children & 7,544 & 13,269 & 20,813 & \\
$\quad$ 0-23 mo & 1,849 & 3,785 & & $27.07 \%$ \\
$\quad 24-35$ mo & 2,574 & 4,321 & & $33.13 \%$ \\
$\quad$ 3-5 y & 3,121 & 5,163 & & $39.80 \%$ \\
CACFP participation & 253 & 162 & 517 & $80.27 \%$ \\
Residence/location & & & 517 & \\
$\quad$ Urban classification & 143 & 101 & & $47.20 \%$ \\
$\quad$ Rural classification & 171 & 102 & & $52.80 \%$ \\
\hline
\end{tabular}

Abbreviations: CACFP, Child and Adult Care Food Program; CCC, childcare center;

$\mathrm{FCCH}$, family childcare home.

a. All the school-aged children ( $>5$ years old) were excluded from the analysis.

from these CCCs and FCCHs (Table 2). Overall $47.2 \%$ of childcare settings were located in urban areas, and $52.8 \%$ of childcare settings were located in rural areas. About $80 \%$ of the 517 childcare settings reported CACFP participation. The CCCs and FCCHs demographic data were significantly different by CACFP participation $(P<.01)$.

\section{Comparison of urban CCCs and FCCHs}

When comparing differences in urban CCCs and FCCHs, significant differences were found for 6 items related to PA and the outdoor play environment (Table 3). Urban CCCs reported higher levels of offering portable play equipment for children during indoor free playtime $(F(1,241)=9.54, P=.0023)$; offering families information on children's PA and outdoor play $(F(1,241)=4.69, P=.0017 ; F(1,241)=3.76, P=$ .0020); and completing professional development on outdoor play and learning $(F(1,241)=4.15, P=.0015)$. Urban $\mathrm{FCCH}$ reported significantly higher levels of supervising, verbally encouraging and participating in children's PA $(F(1,241)=10.21, P=.0026)$ and offering enough portable play equipment for each child $(F(1,241)=12.34, P$ $=.0021)$. 
Table 3. Significant Effects for Physical Activity and Outdoor Play in Urban and Rural CCCs and $\mathrm{FCCHs}$

\section{df, df Error $\quad F \quad P \quad$ Setting Means}

\section{Urban}

Infant and child physical activity

Time provided

Indoor play environment

Offering portable play equipment to children during indoor free playtime

$\begin{array}{lllll}1,241 & 9.54 & .0023^{b} & \text { FCCH } & 3.21\end{array}$

aily practices

Supervising, verbally encouraging and participating in children's physical activity

Education and professional development

Offering families information on children's $\quad 1,24$

$1,241 \quad 10.21 \quad .0026^{\mathrm{b}} \quad \mathrm{FCCH} \quad 3.45$

$.0017^{b} \quad \mathrm{FCCH} \quad 2.50$ physical activity

Policy ${ }^{\mathrm{a}}$

Outdoor play and learning

Outdoor playtime ${ }^{a}$

Outdoor play environment

Offering enough portable play equipment so that it is available for each child

1,241

$12.34 \quad .0021^{\mathrm{b}}$

$\mathrm{FCCH} \quad 3.64$

Education and professional development

Completing professional development on outdoor play and learning

1,241

$4.15 \quad .0015^{b} \quad \mathrm{FCCH} \quad 2.41$

Offering families information on children's physical activity

1,241

$3.76 \quad .0020^{\mathrm{b}}$

CCC 2.73

$\mathrm{FCCH} \quad 2.10$

CCC $\quad 2.42$

\section{Rural}

Infant and child physical activity

Time provided indoor and outdoor physical activity

Indoor play environment

Offering portable play equipment to children during indoor free playtime

$\begin{array}{lllll}1,270 & 6.25 & .0013^{\mathrm{b}} & \mathrm{FCCH} & 3.15\end{array}$

CCC 2.83

Daily practice ${ }^{a}$

Education and professional development

Offering families information on children's physical activity

1,270

$9.67 \quad .0021^{\mathrm{b}} \quad \mathrm{FCCH} \quad 3.19$

Policy ${ }^{\mathrm{a}}$

$3.72 .0014^{\mathrm{b}} \quad \mathrm{FCCH}$

2.20

CCC

2.63

Outdoor play and learning

Outdoor playtime

Outdoor play environment

The open area used for outdoor games and group activities is large enough for children

1,270

11.56

.0025

$\mathrm{FCCH}$

3.46

Education and professional development

Completing professional development on

1,270

$4.83 \quad .0017^{b}$

CCC $\quad 3.15$

outdoor play and learning

Abbreviations: CCC, childcare center; FCCH, family childcare home.

a. Indicates no significant differences were found in this section.

b. Significant difference $(P<.003)$; Sidak-Bonferroni correction was applied. 


\section{Comparison of rural CCCs and FCCHs}

Five items were significantly different when comparing rural CCCs and FCCHs (Table 3). Rural CCCs reported offering more portable play equipment during indoor free playtime $(F(1,270)=9.67, P=.0021)$; offering families information on children's PA $(F(1,270)=3.72, P=$ .0014); and completing professional development on outdoor play and learning $(F(1,270)=4.83, P=.0017)$. Rural FCCHs scored higher than CCCs in regard to the amount of daily time provided for children's indoor and outdoor PA $(F(1,6.25)=9.67, P=.0013)$ and availability of a large space for outdoor games and group activities $(F(1,270)=$ $11.56, P=.0025)$.

\section{Comparison of urban and rural CCCs}

In regard to urban and rural CCCs, significant differences on 8 items were found (Table 3). For all 8 items, urban CCCs reported higher scores than their rural counterparts. Specifically, urban CCCs reported higher levels of daily adult-led PA time $(F(1,200)=5.49, P=.0018)$; removal of children from active playtime for no longer than 5 minutes $(F(1,200)=13.97, P=.0015)$; using PA during daily routines, transitions, and planned activities $(F(1,200)=10.15, P=.0021)$; leading planned lessons for children focused on building gross motor skills $(F(1,200)=12.24, P=.0016)$; having a written policy on PA including a variety of topics $(F(1,200)=4.26, P=.0021)$; providing ample shade in outdoor play spaces $(F(1,200)=10.69, P=.0010)$; providing a variety of portable outdoor play equipment $(F(1,200)=12.77, P=$ $.0013)$; and offering families information on outdoor play and learning $(F(1,200)=4.14, P=.0024)$.

\section{Comparison of urban and rural FCCHs}

Differences in urban and rural FCCHs were also found for 7 items (Table 4). Similar to differences in urban and rural CCCs, urban FCCHs reported higher scores on all items. Urban FCCHs reported significantly higher amounts of daily adult-led PA $(F(1,311)=5.67, P=$ .0014); availability of indoor and outdoor portable play equipment $(F(1,311)=5.67, P=.0022 ; F(1,311)=12.61, P=.0016)$; amount of 
Table 4. Significant Effects for Physical Activity and Outdoor Play in Urban and Rural CCCs

\section{df, df Error}

Location Means

\section{CCCs}

Infant and child physical activity

Time provided

Amount of daily adult-led physical activity provided

Indoor play environment ${ }^{\mathrm{b}}$

Daily practices

Removal of children from active playtime for longer than 5 min

Using physical activity during daily routines, transitions, and planned activities

1,200

$\begin{array}{llll}5.49 & .0018^{a} & \text { Urban } & 2.92 \\ & & \text { Rural } & 2.50\end{array}$

Education and professional development

Leading planned lessons for children focused on building gross motor skills

1,200

1,200

$13.97 .0015^{a}$

Urban

3.59

Policyb

Having a written policy on physical activity including a variety of topics

$10.15 .0010^{a}$

Rural

3.13

Urban $\quad 3.27$

Rural $\quad 2.85$

$12.24 \quad .0016^{\mathrm{a}} \quad$ Urban $\quad 3.56$

Rural $\quad 3.12$

1,200

4.26

Urban $\quad 2.57$

Rural $\quad 2.21$

Outdoor play and learning

Outdoor playtime ${ }^{b}$

Outdoor play environment

Providing ample shade in the outdoor play 1, 200 space

1,200

Providing a variety of portable play equipment in good condition

Education and professional development

Offering families information on outdoor play $\quad 1,200$ and learning

$\begin{array}{llll}10.69 & .0010^{a} & \text { Urban } & 3.26 \\ & & \text { Rural } & 2.89 \\ 12.77 & .0013^{a} & \text { Urban } & 3.58 \\ & & \text { Rural } & 3.10 \\ & & & \\ 4.14 & .0024^{a} & \text { Urban } & 2.42 \\ & & \text { Rural } & 2.13\end{array}$

\section{FCCHs}

Infant and child physical activity

Time provided

Amount of daily adult-led physical activity

1,311

$5.67 \quad .0014^{a}$

Urban $\quad 2.98$

Indoor play environment

Availability of indoor portable play equipment

1,311

Rural

2.52 in good condition

Daily practices

Supervising, verbally encouraging, and participating in children's physical activity

Using physical activity during daily routines, transitions, and planned activities

Education and professional development

Offering families information on children's

Policy ${ }^{b}$ physical activity

1,31

$\begin{array}{llll}10.62 & .0025^{\mathrm{a}} & \text { Urban } \quad 3.47\end{array}$

Rural 3.15

$\begin{array}{llll}1,311 & 9.88 \quad .0010^{a} & \text { Urban } & 3.25\end{array}$

Rural $\quad 2.82$

1,311

$4.53 \quad .0019$

Urban 2.63

Rural $\quad 2.21$

Outdoor play and learning

Outdoor playtime ${ }^{b}$

Outdoor play environment

Providing a variety of portable play equipment in good condition

Offering enough portable play equipment so that it is available for each child

$12.61 .0016^{a}$

Urban

3.55

1,311

$14.53 .0020^{a}$

Rural $\quad 3.13$

Urban $\quad 3.65$

Rural $\quad 3.33$

a. Significant difference $(\mathrm{P}<0.003)$; Sidak-Bonferroni correction was applied.

b. Indicates no significant differences were found in this section. 
outdoor portable play equipment for each child $(F(1,311)=14.53$, $P=.0020)$; supervising, verbal encouragement and participation in children's PA $(F(1,311)=10.62, P=.0025)$; using PA during daily routines, transitions, and planned activities $(F(1,311)=9.88, P=.0010)$; and offering families information on children's PA $(F(1,311)=4.53, P$ $=.0019)$.

\section{Discussion}

This study found that CCCs compared with FCCHs and urban compared with rural facilities tended to fare better in policies and practices that promote children's PA. When comparing urban facilities, CCCs reported significantly higher best practices for PA than FCCHs on 4 items including completing professional development on outdoor play. Urban FCCHs scored higher than urban CCCs on 2 items including supervising, encouraging, and participating in PA. Previous research both confirms and conflicts our findings, as Kim and colleagues ${ }^{21}$ found that $\mathrm{FCCH}$ providers were more likely to receive training, be involved with health activities (e.g., teaching children about PA), and believe they had greater influence on children's health behaviors compared with CCC. Importantly, involvement of staff in physical activities and verbal encouragement has been associated with meeting best practice standards for availability of outdoor playtime and offers other potential benefits including opportunities to work on fundamental movement skills, educational active curriculum, and inclusion of children who are not typically active, as well as increased engagement in PA by children. ${ }^{49}$ Thus, these behaviors should be addressed in urban CCCs. Potentially due to the increased number of staff at CCCs, providers may not feel as inclined to participate with children; however, further investigation is needed to determine why a difference exists as well as how to improve it.

Within the rural setting, we also found that rural CCCs had significantly higher scores in 3 areas while FCCHs had higher scores in 2 areas. Two such areas in which CCCs scored higher were offering portable indoor play equipment and offering families information on children's PA. Research in rural CCCs has suggested to improve and sustain PA there is a need to continue to provide financial resources for the purchase of equipment or workshops as well as training on 
how to support parental outreach on PA topics. ${ }^{30,34}$ Due to potential geographic isolation in rural communities and lack of resources available, unique partnerships with schools, colleges/universities, health departments, churches, hospitals, or physician's offices may be needed to support the provision of resources and professional development for both rural CCCs and FCCHs. ${ }^{30}$ This is especially important, as staff education and training as well as offering portable play equipment can greatly influence the activity levels of children. ${ }^{14,15}$ Specifically, continuing development of relationships between rural health departments or extension offices and providers could be an ideal avenue of support for helping providers identify specific resources they may need. ${ }^{34}$

Previous research comparing FCCHs and CCCs found that CCCs were more likely to report offering a variety of fixed and portable play equipment. ${ }^{23}$ Our study adds to these findings showing that both urban and rural CCCs were more likely to offer portable play equipment during indoor playtime. Interestingly, other research has found no difference in the indoor PA levels between facility types. ${ }^{50}$ As this was based on the director's self-report, additional research is needed to examine the influence of portable play equipment on children's objectively measured PA.

It was also found, when comparing urban and rural FCCHs as well as urban and rural CCCs, urban facilities scored higher on all significantly different items (8 and 7, respectively). Interestingly, approximately half of the items on which urban facilities scored higher appeared to be able to be addressed by training opportunities (e.g., adult-led PA), while the other half required funding or resources (e.g., indoor/outdoor equipment). Given that other research has also found that rural CCCs offered limited structured PA; lacked parental outreach and staff training; and lacked resources needed to best support PA, as mentioned earlier efforts specifically targeting rural providers are needed. ${ }^{30}$ Future work could explore how to allow rural counterparts (i.e., CCC and FCCH) to collaborate and learn from one another through professional development opportunities. ${ }^{49}$ Additionally as other research has noted a positive relationship between providers' own self-efficacy for PA and the provision of PA in childcare, additional efforts may be needed to improve providers' self-efficacy for PA to improve their use of environmental supports. ${ }^{21,39,51}$ 
To encourage more providers to meet best practices for PA, the Centers for Disease Control and Prevention and others have recommended that PA quality metrics be included within statewide systems. ${ }^{52-54}$ Consistent with this recommendation, Nebraska recently launched its first quality rating improvement system called Step Up to Quality, a 5-step system to assist childcare programs in offering highquality childcare. Programs interested in achieving step 2 or higher must complete the online Go NAP SACC orientation video and preself-assessment. Programs interested in achieving step 3 and higher have the option to complete additional Go NAP SACC elements (e.g., attend trainings, complete action plans, and post-self-assessment) to earn points toward a higher step rating. While other research has not found differences in PA best practices based on quality ratings, ${ }^{55}$ this is worth future research. Additionally, as there are currently no PA standards related to licensing in Nebraska, working with licensing and regulation is another recommended strategy for improving PA in childcare settings. ${ }^{51,52}$

There were several limitations to this study that warrant consideration. The primary limitation of this study is the self-report nature of the survey. This study may be subject to social desirability bias; thus, providers may have overreported their PA policies and practices. However, previous studies assessing reliability and validity of this instrument have found the tool to be accurate for use in childcare. ${ }^{38}$ Since this was a convenience sample, selection bias may also be a concern and results may not be representative of all CCCs and FCCHs in the state and providers who are more likely to meet standards may have been more likely to participate. Further, we did not collect information on amount of time working at an early childhood facility, gender, age, race/ethnicity, participation in other professional development, or participation in the state's quality rating improvement system. Additional research is needed utilizing a more representative sample. For CCCs, reports were typically completed by site directors and they may not be involved in the actual implementation of the practices within the assessment. Also, Nebraska's unique geography may not allow for generalizability to other states. Finally, as definitions of rural and urban can vary, findings may differ when utilizing different definitions. ${ }^{56}$ Strengths of this article include the large sample size as well as ability to compare childcare organization type (CCC vs FCCH) and 
geographic location (urban vs rural). Despite limitations, this study fills an important gap in the literature regarding the need for the provision of unique supports for childcare based on type of setting and geographic location.

\section{Conclusion}

Even though Go NAP SACC has shown to successfully improve PA policies and practices and that these changes can be maintained, additional efforts are needed to ensure the program is well suited for the local population. ${ }^{57,58} \mathrm{As}$ noted in previous research, the relationship between urban-rural status and health behaviors is complex. ${ }^{59}$ Rural settings in particular may be in need of unique and creative approaches to improve health outcomes. ${ }^{56}$ Our findings provide evidence that it is critical to understand baseline differences in childcare structures to assist providers, state leaders, and early childhood stakeholders identify strategies and/or resources to best support childcare institutions of various sizes and in geographic locations. Specific attention and resources should be allotted for rural providers, especially those in FCCHs. While differences in mean scores may appear minimal, these minor changes could make important strides for helping providers meet best practices and better promote PA.

Acknowledgments The authors would like to thank all of the childcare providers in Nebraska who took part in the Go NAP SACC baseline self-assessment.

Funding This project was supported by the Cooperative Agreement Number NU58DP004819, funded by the Centers for Disease Control and Prevention. Its contents are solely the responsibility of the authors and do not necessarily represent the official views of the Centers for Disease Control and Prevention or the Department of Health and Human Services. This work was also supported by a Nebraska Department of Health and Human Services Child Care and Development Fund, USDA Nebraska Team Nutrition, and a Title V Maternal and Child Health Block Grant.

Disclosures The authors declare they have no competing financial interests. 


\section{References}

1. World Health Organization. Report of the commission on ending childhood obesity. https://www.who.int/end-childhood-obesity/publications/echo-report/ en/ Published 2016. Accessed January 20, 2019.

2. Ogden $\mathrm{CL}$, Carroll MD, Kit BK, Flegal KM. Prevalence of childhood and adult obesity in the united states, 2011-2012. JAMA. 2014;311(8):806-814.

3. Cook S, Weitzman M, Auinger P, Nguyen M, Dietz WH. Prevalence of a metabolic syndrome phenotype in adolescents: findings from the third national health and nutrition examination survey, 1988-1994. Arch Pediatr Adolesc Med. 2003;157(8):821-827.

4. Hanevold C, Waller J, Daniels S, Portman R, Sorof J, International Pediatric Hypertension Association. The effects of obesity, gender, and ethnic group on left ventricular hypertrophy and geometry in hypertensive children: a collaborative study of the international pediatric hypertension association. Pediatrics. 2004;113(2):328-333.

5. Weiss R, Dziura J, Burgert TS, et al. Obesity and the metabolic syndrome in children and adolescents. N Engl J Med. 2004;350(23):2362-2374.

6. United States Department of Health and Human Services. Physical Activity Guidelines for Americans. 2nd ed. Washington, DC: US Department of Health and Human Services; 2018. https://health.gov/paguidelines/second-edition/ pdf/Physical Activity Guidelines 2nd edition.pdf Accessed March 12, 2020.

7. HealthyPeople.gov. Healthy People 2020 Topics \& Objectives: Physical Activity. https://www.healthypeople.gov/2020/topics-objectives/topic/physical-activity/ objectives Accessed April 3, 2020.

8. National Physical Activity Plan. Education. https://www.physicalactivityplan.org/ theplan/education/education st4.html Accessed April 3, 2020.

9. Head Start Early Childhood Learning and Knowledge Center. Effective Practice Guidelines: Perpetual, Motor, and Physical Development. https://eclkc.ohs. acf.hhs.gov/school-readiness/effective-practice-guides/perceptual-motorphysical-development Accessed April 3, 2020.

10. United States Census Bureau. Child care costs on the upswing, census bureau reports. https://www.census.gov/newsroom/press-releases/2013/cb13-62.html Published 2013. Accessed April 3, 2020.

11. National Center for Education Statistics. Enrollment of 3-, 4-, and 5-year-old children in preprimary programs, by age of child, level of program, control of program, and attendance status: selected years, 1970 through 2015. https:// nces.ed.gov/programs/digest/d16/tables/dt16 202.10.asp?current=yes Updated 2016. Accessed November 17, 2016.

12. Burchinal MR, Roberts JE, Riggin R, Jr, Zeisel SA, Neebe E, Bryant D. Relating quality of center-based child care to early cognitive and language development longitudinally. Child Dev. 2000;71(2):339-357.

13. Belsky J, Vandell DL, Burchinal $M$, et al. Are there long-term effects of early child care? Child Dev. 2007;78(2):681-701. 
14. Bower JK, Hales DP, Tate DF, Rubin DA, Benjamin SE, Ward DS. The childcare environment and children's physical activity. Am J Prev Med. 2008;34(1):23-29.

15. Trost SG, Ward DS, Senso M. Effects of child care policy and environment on physical activity. Med Sci Sports Exerc. 2010;42(3):520-525.

16. Trost SG, Messner L, Fitzgerald K, Roths B. Nutrition and physical activity policies and practices in family child care homes. Am J Prev Med. 2009;37(6):537-540.

17. Ward DS. Physical activity in young children: the role of child care. Med Sci Sports Exerc. 2010;42(3):499-501.

18. Timmons BW, Leblanc AG, Carson V, et al. Systematic review of physical activity and health in the early years (aged 0-4 years). Appl Physiol Nutr Metab. 2012;37(4): 773-792.

19. Pate RR, O'Neill JR, Brown WH, Pfeiffer KA, Dowda M, Addy CL. Prevalence of compliance with a new physical activity guideline for preschool-age children. Child Obes. 2015;11(4):415-420.

20. Office of Personnel Management. Work-life reference materials: child care resources handbook. https://www.opm.gov/policy-data-oversight/worklife/ referencematerials/child-care-resources-handbook/\#content Updated 2016. Accessed March 14, 2019.

21. Kim J, Shim JE, Wiley AR, Kim K, McBride BA. Is there a difference between center and home care providers' training, perceptions, and practices related to obesity prevention? Matern Child Health J. 2012;16(8):1559-1566.

22. Rosenthal M, Crowley A, Curry L. Family child care providers' experience in health promotion. Fam Community Health. 2008;31(4):326-334.

23. Tandon PS, Garrison MM, Christakis DA. Physical activity and beverages in home-and center-based child care program. J Nutr Educ Behav. 2012;44(4):355-359.

24. Cosco NG. Motivation to move: physical activity affordance in preschool play areas. https://era.ed.ac.uk/handle/1842/5904 Published 2006.

25. Liu J, Bennett KJ, Harun H, Probst JC. Urban-rural differences in overweight status and physical inactivity among US children aged 10-17 years. J Rural Health. 2008;24(4):407-415.

26. Grace C, Shores E, Zaslow M, Brown B, Aufseeser D, Bell L. Rural disparities in baseline data of the early childhood longitudinal study: a chart book (rural early childhood report no. 3). National Center for Rural Early Childhood Learning Initiatives. https://www.semanticscholar.org/paper/Rural-Disparitiesin-Baseline-Data-of-the-Early-A-Grace-Shores/1291a963029ed9173ed6e094c0 $\underline{\text { 8dfa63471d7d35? citationIntent=methodology\#citng-papers }}$ Published 2006. Accessed April 11, 2020.

27. Patterson PD, Moore CG, Probst JC, Shinogle JA. Obesity and physical inactivity in rural America. J Rural Health. 2004;20(2):151-159.

28. Probst JC, Barker JC, Enders A, Gardiner P. Current state of child health in rural America: How context shapes children's health. J Rural Health. 2018;34(suppl 1): S3-S12. 
29. Rice K, Sisson S, Schuna J. Comparison of physical activity levels among children attending urban or rural childcare. 3402 Board \# 163 May 30, 800AM930 AM. Med Sci Sports Exerc. 2015;47(5S):919.

30. Foster JS, Contreras D, Gold A, et al. Evaluation of nutrition and physical activity policies and practices in child care centers within rural communities. Child Obes. 2015;11(5):506-512.

31. Kenney E, Cradock A, Resch S, Giles C, Gortmaker S. The Cost-Effectiveness of Interventions for Reducing Obesity Among Young Children through Healthy Eating, Physical Activity, and Screen Time. Durham, NC: Healthy Eating Research; 2019. https://healthyeatingresearch.org/wp-content/ uploads/2019/03/her kenney brief-3.pdf

32. Alkon A, Crowley AA, Neelon SEB, et al. Nutrition and physical activity randomized control trial in child care centers improves knowledge, policies, and children's body mass index. BMC Public Health. 2014;14:215.

33. McWilliams C, Ball SC, Benjamin SE, Hales D, Vaughn A, Ward DS. Best-practice guidelines for physical activity at child care. Pediatrics. 2009;124(6):1650-1659.

34. Battista RA, Oakley H, Weddell MS, Mudd LM, Greene JB, West ST. Improving the physical activity and nutrition environment through self-assessment (NAP SACC) in rural area child care centers in North Carolina. Prev Med. 2014;67(suppl 1):S10-S16.

35. Ward DS, Benjamin SE, Ammerman AS, Ball SC, Neelon BH, Bangdiwala SI. Nutrition and physical activity in child care: results from an environmental intervention. Am J Prev Med. 2008;35(4):352-356.

36. Ammerman AS, Ward DS, Benjamin SE, et al. An intervention to promote healthy weight: Nutrition and Physical Activity Self-assessment for Child Care (NAP SACC) theory and design. Prev Chronic Dis. 2007;4(3):A67.

37. Benjamin SE, Ammerman A, Sommers J, Dodds J, Neelon B, Ward DS. Nutrition and Physical Activity Self-assessment for Child Care (NAPSACC): results from a pilot intervention. J Nutr Educ Behav. 2007;39(3):142-149.

38. Benjamin SE, Neelon B, Ball SC, Bangdiwala SI, Ammerman AS, Ward DS. Reliability and validity of a nutrition and physical activity environmental selfassessment for child care. Int J Behav Nutr Phys Act. 2007;4: 29.

39. Dinkel D, Dev D, Guo Y, et al. Improving the physical activity and outdoor play environment of family child care homes in Nebraska through go nutrition and physical activity self-assessment for child care. J Phys Act Health. 2018;15(10):730-736.

40. Nutrition and Physical Activity Self-Assessment for Child Care Go NAP SACC, The University of North Carolina at Chapel Hill. Our History. https://gonapsacc. org/history Published 2018. Accessed March 30, 2020.

41. Ward D, Morris E, McWilliam C, et al. Go NAP SACC: Nutrition and Physical Activity Self-Assessment for Child Care. 2nd ed. Chapel Hill, NC: Center for Health Promotion and Disease Prevention and Department of Nutrition, University of North Carolina at Chapel Hill; 2014. 
42. US Department of Agriculture. Child and Adult Care Food Program. https:// www.fns.usda.gov/cacfp/child-and-adult-care-food-program Updated 2013. Accessed April 3, 2020.

43. Lin G, Qu M. Smart Use of State Public Health Data for Health Disparity Assessment. Boca Raton, FL: CRC Press; 2016.

44. Frampton AM, Sisson SB, Horm D, Campbell JE, Lora K, Ladner JL. What's for lunch? An analysis of lunch menus in 83 urban and rural Oklahoma childcare centers providing all-day care to preschool children. J Acad Nutr Diet. 2014; 114(9):1367-1374.

45. Nutrition and Physical Activity Self Assessment for Child Care Go NAP SACC, The University of North Carolina at Chapel Hill. Self Assessments. https:// gonapsacc.org/self-assessment-materials Accessed March 29, 2020.

46. Trost SG, Messner L, Fitzgerald K, Roths B. A nutrition and physical activity intervention for family child care homes. Am J Prev Med. 2011;41(4):392-398.

47. Nebraska GO NAP SACC. Nebraska nutrition and physical activity selfassessment. http://negonapsacc.unl.edu/ Accessed August 1, 2017.

48. Abdi H. Bonferroni and Šidák corrections for multiple comparisons. In: Salkind NJ, ed. Encyclopedia of Measurement and Statistics. Thousand Oaks, CA: Sage; 2007:103-107.

49. Gubbels JS, Kremers SPJ, van Kann DHH, et al. Interaction between physical environment, social environment, and child characteristics in determining physical activity at child care. Health Psychol. 2011;30(1):84-90.

50. Natale R, Page M, Sanders L. Nutrition and physical activity practices in childcare centers versus family childcare homes. Early Childhood Educ J. 2014;42(5): 327-334.

51. Figueroa R, Wiley A. Factors associated with time provided to children for physical activity in family child care: a cross-sectional study. Springerplus. 2016;5(1):1730.

52. Tandon PS, Saelens BE, Copeland KA. A comparison of parent and childcare provider's attitudes and perceptions about preschoolers' physical activity and outdoor time. Child Care Health Dev. 2017;43(5):679-686.

53. Kaphingst KM, Story M. Child care as an untapped setting for obesity prevention: state child care licensing regulations related to nutrition, physical activity, and media use for preschool-aged children in the united states. Prev Chronic Dis. 2009;6(1):A11.

54. Centers for Disease Control and Prevention. Spectrum of opportunities for obesity prevention in the early care and education setting (ECE) CDC technical assistance briefing document. https://www.cdc.gov/obesity/strategies/earlycare-education/pdf/TheSpectrumofOpportunitiesFramework May2018 508.pdf Accessed March 14, 2019.

55. Tandon PS, Walters KM, Igoe BM, Payne EC, Johnson DB. Physical activity practices, policies and environments in Washington state child care settings: results of a statewide survey. Matern Child Health J. 2017;21(3): 571-582. 
56. Wheeler SB, Davis MM. "Taking the bull by the horns": four principles to align public health, primary care, and community efforts to improve rural cancer control. J Rural Health. 2017;33(4):345-349.

57. Martin SL. The Maine nutrition and physical activity self assessment for childcare (NAP SACC) experience. J Child Adol Beh. 2014;2(1):122.

58. Smith T, Blaser C, Geno-Rasmussen $C$, et al. Improving nutrition and physical activity policies and practices in early care and education in three states, 20142016. Prev Chronic Dis. 2017;14:E73.

59. Sage R, Ward B, Myers A, Ravesloot C. Transitory and enduring disability among urban and rural people. J Rural Health. 2019;35(4):460-470. 